\title{
Prognosis of men with high-risk prostate cancer stratified by risk factors: a population-based retrospective cohort study
}

\author{
Pan Song ${ }^{1 \#}$, Jiaxiang Wang ${ }^{2 \#}$, Mengxuan $\mathrm{Shu}^{2}$, Xiaoyu $\mathrm{Di}^{3}$, Yaxin $\mathrm{Li}^{3}$, Yuxin Qing ${ }^{3}$, Qiang Dong ${ }^{1}$ \\ ${ }^{1}$ Department of Urology, West China Hospital of Sichuan University, Chengdu, China; ${ }^{2}$ The First Clinical Medical College, Lanzhou University, \\ Lanzhou, China; ${ }^{3}$ The Second Clinical Medical College, Lanzhou University, Lanzhou, China \\ Contributions: (I) Conception and design: Q Dong; (II) Administrative support: Q Dong; (III) Provision of study materials or patients: P Song, J \\ Wang; (IV) Collection and assembly of data: P Song, J Wang; (V) Data analysis and interpretation: P Song, J Wang, M Shu, X Di, Y Li, Y Qing; (VI) \\ Manuscript writing: All authors; (VII) Final approval of manuscript: All authors. \\ \#These authors contributed equally to this work. \\ Correspondence to: Qiang Dong. Department of Urology, West China Hospital of Sichuan University, No. 37, Guoxue Lane, Wuhou District, \\ Chengdu, China. Email: dqiang666@163.com.
}

Background: The aim was to evaluate the prognosis of men with all possible high-risk prostate cancers (PCa) stratified by risk factors.

Methods: Within the Surveillance, Epidemiology and End Results (SEER) database from 2004 to 2015 , men with non-metastasis high-risk PCa were identified. Kaplan-Meier analysis and Cox regressions were adopted to evaluate the overall survival (OS) and prostate cancer-specific survival (PCSS). Nomograms were conducted to build a predictive model. Concordance index (C-index) and calibration curves were used to validate the model.

Results: A total of 151,799 patients were included. Seven risk groups were divided including one highrisk factor of T3-4 (A1), prostate-specific antigen (PSA) >20 ng/mL (A2), and Gleason score (GS) 8-10, two high-risk factors of T3-4 PSA >20 ng/mL (B1), T3-4 GS 8-10 (B2), PSA >20 ng/mL GS 8-10 (B3), and three high-risk factors of T3-4 PSA > $20 \mathrm{ng} / \mathrm{mL}$ GS 8-10 (C). The survival curves of PCSS showed that A1 was the best among all groups. A2, A3 and B1 had similar results and were all better than B2 [with A2 as reference, A3 hazard ratio (HR): 1.09 (1.02-1.17), $\mathrm{P}=0.046$; B1 HR: 0.93 (0.82-1.05), $\mathrm{P}=0.103$; B2 HR: 1.42 (1.32-1.53), $\mathrm{P}<0.001]$. There is no significant difference between $\mathrm{B} 3$ and $\mathrm{C}$ [HR: 0.94 (0.86-1.03), $\mathrm{P}=0.029$ ] and these two present the worst survival in prognosis. The 10-year PCSS of A1, A2, A3, B1, B2, B3, and C groups were $95.8 \%, 86.9 \%, 86.1 \%, 86.9 \%, 80.8 \%, 64.7 \%$ and $65.6 \%$, respectively. Three simplified groups were divided including a good prognosis group (A1), an intermediate prognosis group (A2, A3, B1 and B2), and a poor prognosis group (B3 and $\mathrm{C}$ ). Compared to the good prognosis group, the HR of the intermediate and the poor prognosis group were 4.21 (3.96-4.48), $\mathrm{P}<0.001$ and 11.36 (10.59-12.19), $\mathrm{P}<0.001$. A nomogram was built based on these factors. The C-index of the nomogram was 0.772 , indicating a good accuracy of the model.

Conclusions: Men with the combination of PSA > $20 \mathrm{ng} / \mathrm{mL}$ and GS 8-10 had the worst PCSS among all patients. PCa with three high-risk factors was not more aggressive than that with two high-risk factors of GS 8-10 and PSA >20 ng/mL.

Keywords: Prostate cancer (PCa); high-risk factors; prognosis; Surveillance, Epidemiology and End Results (SEER)

Submitted Mar 19, 2020. Accepted for publication Aug 05, 2020.

doi: $10.21037 /$ tcr-20-1578

View this article at: http://dx.doi.org/10.21037/tcr-20-1578 


\section{Introduction}

Prostate cancer $(\mathrm{PCa})$ is the most common malignancy in the male genitourinary system, making up about $15 \%$ of all malignant tumors in the world $(1,2)$. In 2019, it is estimated that there are 174,650 men newly diagnosed with $\mathrm{PCa}$ and 31,620 deaths of PCa in the United States (3). In spite of increased screenings by prostate-specific antigen (PSA), a fair proportion of patients are still at high-risk stages (4). Although many risk stratification schemes and nomograms have been reported recently $(5,6)$, the most commonly used stratification is still the one developed by D'Amico et al. (7-9). With the PSA concentration, Gleason score (GS) and tumor-node-metastasis (TNM) staging, the non-metastasis $\mathrm{PCa}$ is commonly classified into low-risk, intermediaterisk and high-risk groups. The high-risk group accounts for about $15 \%$ of PCa diagnoses, and is characterized by recurrence and high cancer-related death. It is one of the important causes of death in PCa diseases (10).

Even though the prognosis of men with high-risk $\mathrm{PCa}$ has been evaluated in many studies, the survival results of patients with detailed high-risk factors of PCa have rarely been reported before. The prognosis of high-risk PCa varies greatly between different risk factors (11). The 5 -year biochemical recurrence (BCR) free survival for men assigned to the high-risk group by clinical T3a stage was $77.8 \%$, by GS $53.7 \%$, and by PSA level $41.0 \%$ (12). Besides, the number of high-risk factors also seriously affect the prognosis of patients. Walz et al. (13) reported that men with one risk factor had a more favorable 5-year BCR-free survival $(50.3 \%)$ than those with two or more risk factors (27.5\%).

A nomogram is a convenient tool for predicting the probability of certain clinical events in an individual patient. It can also be useful for clinical risk stratification, decisionmaking and personalized treatment. The Surveillance, Epidemiology and End Results (SEER) program covers approximately $28 \%$ of all cancer cases of the US population. It incorporates patient demographics, tumor characteristics and treatment from population-based cancer registries.

The aim of this study was to analyze the prognosis of men with all possible high-risk PCa groups, and to construct a predictive model of nomograms to predict survival rates of men with high-risk PCa. We present the following article in accordance with the STROBE reporting checklist (available at http://dx.doi.org/10.21037/tcr-20-1578).

\section{Methods}

\section{Data source}

The data of this study were derived from the SEER database. This database is a population-based cancer registry system. At present, the database has covered about $29 \%$ of cancer patients in the United States, and is one of the most representative large-scale cancer case registration databases in the United States (14). Men with primary PCa diagnosed by prostate puncture or transurethral resection of prostate were retrospectively identified from January 1, 2004, to December 31, 2015. This study was conducted in accordance with the Declaration of Helsinki (as revised in 2013).

\section{Inclusion and exclusion criteria}

Patients were considered eligible if they met the following criteria: (I) primary non-metastasis PCa (cT1-4N0M0). (II) Patients met the definition of high-risk PCa: PSA $>20 \mathrm{ng} / \mathrm{mL}$, or $\mathrm{GS} \geq 8$, or $\geq \mathrm{T} 3 \mathrm{a}$. (III) The survival status at the end of the follow-up were clearly known.

The following criteria were used for data exclusion: (I) multiple tumors; (II) the information of age, PSA, TNM stage, GS or follow-up time were unclear or incomplete.

\section{Variables and main outcomes}

The general characteristics, tumor information, and survival outcomes were collected.

Variables included age, race, marital status, T staging, PSA, GS, treatment, survival time, living state (alive or dead), and PCa-specific living state (alive, died for PCa and died for other reasons). The survival time was defined as the time from the patient's first diagnosis to the patient's death or the last follow-up time (December 31, 2015).

According to the definition of high-risk $\mathrm{PCa}$, the included patients were divided into seven groups. Patients with one high-risk factor were in A1 (T3-4, PSA $\leq 20 \mathrm{ng} / \mathrm{mL}$, GS 2-7), A2 (T1-2, PSA >20 ng/mL, GS 2-7), and A3 (T12 , PSA $\leq 20 \mathrm{ng} / \mathrm{mL}$, GS 8-10). Men with two risk factors were in B1 (T3-4, PSA >20 ng/mL, GS 2-7), B2 (T3-4, PSA $\leq 20 \mathrm{ng} / \mathrm{mL}$, GS 8-10), and B3 (T1-2, PSA $\geq 20 \mathrm{ng} / \mathrm{mL}$, GS 8-10). The group with three high-risk factors was $\mathrm{C}$ (T3-4, PSA > $20 \mathrm{ng} / \mathrm{mL}$, GS 8-10).

The main outcomes in this study were overall survival 
(OS) and prostate cancer-specific survival (PCSS). The survival time was defined as the time from the patient's first diagnosis to the patient's death or the last follow-up time (December 31, 2015).

\section{Statistical analyses}

Baseline characteristics including age, race, marital status, T stage, GS, PSA level, and follow-up time were described in different high-risk groups. The Kaplan-Meier analysis was adopted for the OS and PCSS of men in all high-risk groups. The 5- and 10-year OS and PCSS rate of all groups were calculated with survival tables. Long rank $\mathrm{P}$ values were calculated to determine the statistical significance. Univariate Cox regression model was used to evaluate each variable's parameter in predicting OS and PCSS. Multivariate Cox regression model was conducted for the variables with $\mathrm{P}<0.05$ in univariate analyses.

A nomogram model was built with the coefficients of each factor in the multivariate Cox analysis. Verifications of the nomogram model were performed with the concordance index (C-index), and calibration curves. A C-index was used to evaluate the predictive accuracy of the nomogram. Fiveand 10-year calibration curves were conducted to compare the predicted probability with the observed probability.

All statistical analyses were performed with the software of SPSS version 25 and $\mathrm{R}$ software version 3.2.3. $\mathrm{P}<0.05$ was considered statistically significant.

\section{Results}

\section{Patient characteristics}

In total, 151,799 patients with a median age of 66 [6072] years were included. The 72,143 (47.5\%), 14,979 (9.8\%) and 30,698 (20.2\%) patients were included in A1, A2, and A3 group. The 5,121 (3.4\%), 16,589 (10.9\%), and 7,746 (5.1\%) patients were in B1, B2, and B3 group. The 4,523 patients were in group $\mathrm{C}$. The baseline characteristics were summarized in Table 1.

\section{Survival outcomes}

\section{OS and PCSS}

The 5- and 10-year OS and PCSS rates of the overall cohort were $85.5 \%$ and $65.4 \%$. For the seven groups, the 10 -year OS rate of each group were $82.1 \%, 55.8 \%$, $57.2 \%, 64.4 \%, 60.4 \%, 35.2 \%$ and $44.1 \%$, individually
(Table 2). Patients in A1 group had the best survival results, followed by men in B1, B2, A3, A2, B3, and C group. Men in B3 group was associated with the worst OS among all groups. Significant differences existed among seven groups $(\mathrm{P}<0.001)$. With $\mathrm{A} 1$ group as the reference, the hazard ratio (HR) and $95 \%$ confidence interval (CI) of A2, A3, B1, B2, $\mathrm{B} 3$ and $\mathrm{C}$ group were 3.2 (3.08-3.33), 3.03 (2.93-3.14), 2.44 (2.29-2.61), 2.64 (2.54-2.75), 6.16 (5.91-6.43), 4.87 (4.61-5.15), respectively. The OS curve and HR results were shown in Figure $1 A$ and Table 3.

The 5- and 10-year PCSS rate of the overall cohort were $95.3 \%$ and $88 \%$. The 10 -year PCSS rate of each of these groups were $95.8 \%, 86.9 \%, 86.1 \%, 86.9 \%, 80.8 \%, 64.7 \%$ and $65.6 \%$, respectively (Table 2). Men in A1 group still had the best PCSS, followed by A2, B1, A3, B2, C and B3 group. No significant difference was detected between $\mathrm{A} 2$ and B1 group [HR: 1.08, 95\% CI: (0.95-1.22), P=0.124], as well as between B3 and C group [HR: 0.94, 95\% CI: (0.861.03), $\mathrm{P}=0.057]$. With men in $\mathrm{A} 1$ group as the reference, the HR and $95 \%$ CI of A2, A3, B1, B2, B3 and C group were 3.72 (3.43-4.03), 4.05 (3.78-4.33), 3.44 (3.04-3.9), 5.29 (4.91-5.7), 11.6 (10.74-12.53), 10.95 (10-11.99), respectively. These results were presented in Figure $1 B$ and Table 3.

For the cohort that have received local treatments (LTs), the 10-year OS and PCSS rate were $71 \%$ and $90.6 \%$ (Table 2). The OS curve was shown in Figure 1C, and PCSS curve in Figure 1D. The survival outcomes were similar with those of overall cohort. Men with the best prognosis were in $\mathrm{A} 1$ group and the worst were in $\mathrm{B} 3$ and $\mathrm{C}$ group. The results of the rest groups including A2, A3, B1 and $\mathrm{B} 2$ were close. With A1 group as the reference, the HR and $95 \% \mathrm{CI}$ of $\mathrm{A} 2, \mathrm{~A} 3, \mathrm{~B} 1, \mathrm{~B} 2, \mathrm{~B} 3$ and $\mathrm{C}$ group for PCSS were 2.48 (2.23-2.76), $3.46(3.19-3.75), 2.99(2.55-3.51)$, 5.05 (4.62-5.51), 9.16 (8.27-10.15), 9.82 (8.74-11.04), respectively (Table 3).

According to the OS and PCSS results in all and LT cohort, three simplified groups were divided: a good prognosis group with only one high-risk factor of T3-4 (A1), an intermediate prognosis group with one factor of PSA $\geq 20 \mathrm{ng} / \mathrm{mL}$, or GS 8-10 (A2, A3, B1 and B2), and a poor prognosis group of PSA $\geq 20 \mathrm{ng} / \mathrm{mL}$ and GS $8-10$ with/ without T3-4 (B3 and C). The OS and PCSS curves of the three groups were shown in Figure 2. The 5- and 10-year OS rate of these three groups were $93.7 \%$ vs. $81.2 \%$ vs. $65.5 \%$, and $82.1 \%$ vs. $58.2 \%$ vs. $38.2 \%$, respectively (Table 2). With the good prognosis group as the reference, the HR 
Table 1 Basic characteristics of patients with all possible high-risk factors

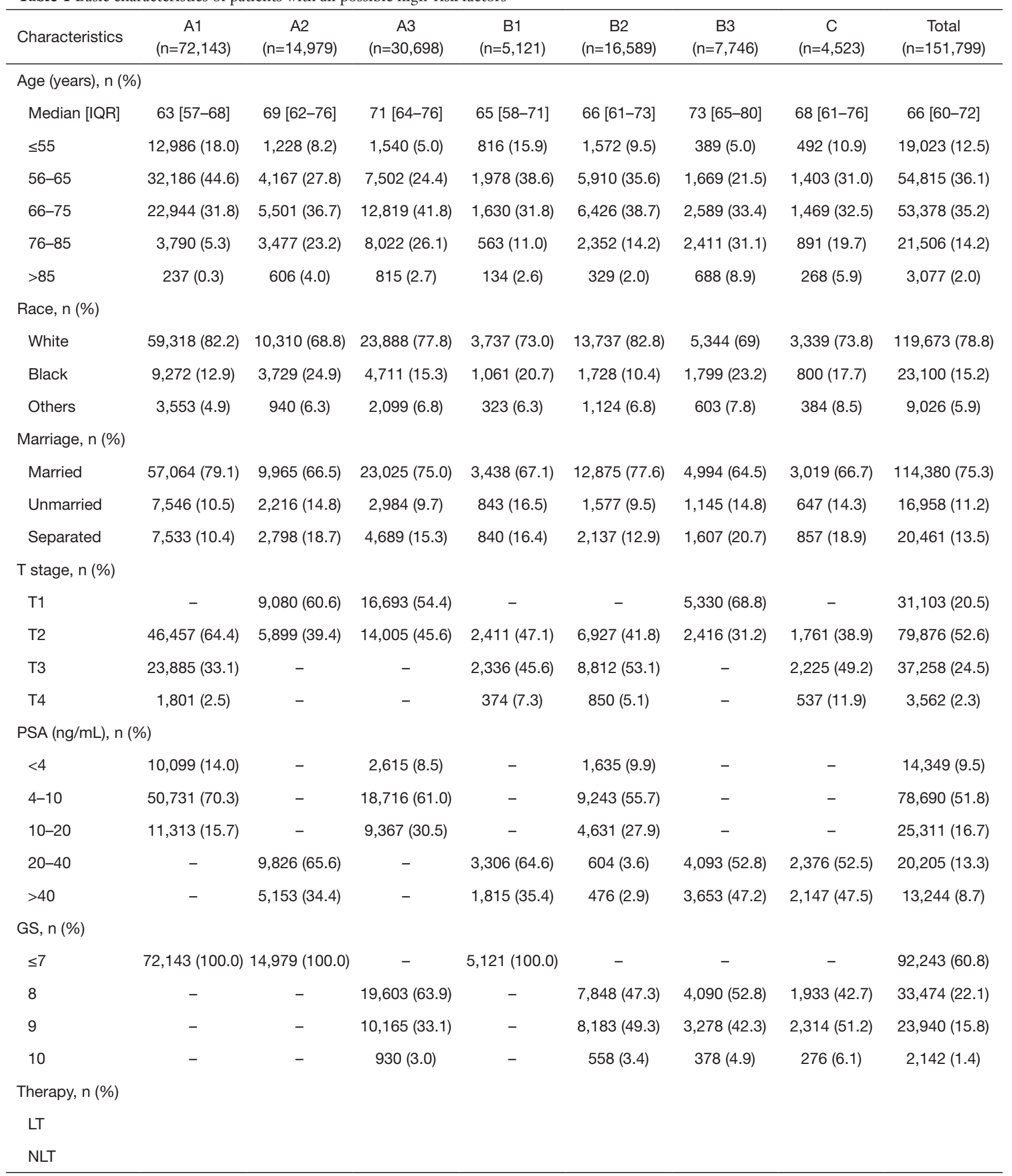

Table 1 (continued) 
Table 1 (continued)

\begin{tabular}{lcccccccc}
\hline Characteristics & $\begin{array}{c}\mathrm{A} 1 \\
(\mathrm{n}=72,143)\end{array}$ & $\begin{array}{c}\mathrm{A} 2 \\
(\mathrm{n}=14,979)\end{array}$ & $\begin{array}{c}\mathrm{A} 3 \\
(\mathrm{n}=30,698)\end{array}$ & $\begin{array}{c}\mathrm{B} 1 \\
(\mathrm{n}=5,121)\end{array}$ & $\begin{array}{c}\text { B2 } \\
(\mathrm{n}=16,589)\end{array}$ & $\begin{array}{c}\text { B3 } \\
(\mathrm{n}=7,746)\end{array}$ & $\begin{array}{c}\text { C } \\
(\mathrm{n}=4,523)\end{array}$ & $\begin{array}{c}\text { Total } \\
(\mathrm{n}=151,799)\end{array}$ \\
\hline RP & $54,124(75.0)$ & $2,496(16.7)$ & $5,896(19.2)$ & $2,455(47.9)$ & $8,313(50.1)$ & $537(6.9)$ & $1,179(26.1)$ & $75,000(49.4)$ \\
EBRT & $8,782(12.2)$ & $6,723(44.9)$ & $17,313(56.4)$ & $1,265(24.7)$ & $4,117(24.8)$ & $3,572(46.1)$ & $1,644(36.3)$ & $43,416(28.6)$ \\
Prostatectomy & $2,574(3.6)$ & $528(3.5)$ & $1,101(3.6)$ & $371(7.2)$ & $1,764(10.6)$ & $382(4.9)$ & $422(9.3)$ & $7,142(4.7)$ \\
Radiation & $4,918(6.8)$ & $3,781(25.2)$ & $4,450(14.5)$ & $704(13.7)$ & $1,291(7.8)$ & $2,129(27.5)$ & $816(18.0)$ & $18,089(11.9)$ \\
COT & $1,648(2.3)$ & $1,097(7.3)$ & $1,544(5.0)$ & $300(5.9)$ & $1,062(6.4)$ & $871(11.2)$ & $391(8.6)$ & $6,913(4.6)$ \\
NDT & $97(0.1)$ & $354(2.4)$ & $394(1.3)$ & $26(0.5)$ & $42(0.3)$ & $255(3.3)$ & $71(1.6)$ & $1,239(0.8)$
\end{tabular}

Follow up (months)

Median [IQR] $\quad 57$ [33-89] $\quad 71$ [37-109] 68 [37-104] $\quad 60$ [32-91] $\quad 62$ [34-93] 46 [24-81] 51 [27-81] 60 [33-93]

A1: T3-4, PSA $\leq 20$ ng/mL, GS 2-7; A2: T1-2, PSA >20 ng/mL, GS 2-7; A3: T1-2, PSA $\leq 20$ ng/mL, GS 8-10; B1: T3-4, PSA >20 ng/mL, GS 2-7; B2: T3-4, PSA $\leq 20$ ng/mL, GS 8-10; B3: T1-2, PSA $\geq 20$ ng/mL, GS 8-10; C: T3-4, PSA >20 ng/mL, GS 8-10. IQR, interquartile range; PSA, prostate-specific antigen; GS, Gleason score; LT, local treatment; NLT, no local treatment; RP, radical prostatectomy; EBRT, external beam radiotherapy; COT, combined therapy; NDT, no definitive therapy.

Table 2 Five- and 10-year OS rates and PCSS rates of different groups

\begin{tabular}{lcccc}
\hline \multirow{2}{*}{ Variables } & \multicolumn{2}{c}{ OS (rate, 95\% Cl) } & \multicolumn{2}{c}{ PCSS (rate, 95\% Cl) } \\
\cline { 2 - 4 } Overall cohort & 5 -year & 10 -year & 5-year & 10-year \\
A1 & $85.5(85.3-85.7)$ & $65.4(65.0-65.8)$ & $95.3(95.1-95.5)$ & $88.0(87.6-88.4)$ \\
A2 & $93.7(93.5-93.9)$ & $82.1(81.5-82.7)$ & $98.9(98.7-99.1)$ & $95.8(95.4-96.2)$ \\
A3 & $79.6(78.8-80.4)$ & $55.8(54.8-56.8)$ & $94.9(94.5-95.3)$ & $86.9(86.1-87.7)$ \\
B1 & $80.7(80.3-81.1)$ & $57.2(56.4-58.0)$ & $94.2(93.8-94.6)$ & $86.1(85.5-86.7)$ \\
B2 & $84.2(83.0-85.4)$ & $64.4(62.2-66.6)$ & $95.3(94.5-96.1)$ & $86.6(85.1-88.7)$ \\
B3 & $82.9(82.3-83.5)$ & $60.4(59.2-61.6)$ & $92.0(91.4-92.6)$ & $80.8(79.8-81.8)$ \\
C & $63.6(62.4-64.8)$ & $35.2(33.6-36.8)$ & $81.7(80.5-82.9)$ & $64.7(62.9-66.5)$ \\
Cohort with LTs & $67.4(65.8-69.0)$ & $44.1(41.7-46.5)$ & $81.9(80.5-83.3)$ & $65.6(40.1-91.1)$ \\
Good prognosis group & $89.2(89.0-89.4)$ & $71.0(70.6-71.4)$ & $96.7(96.5-96.9)$ & $90.6(90.2-91.0)$ \\
Intermediate prognosis group & $81.2(80.8-81.6)$ & $58.2(57.6-58.8)$ & $93.8(93.6-94.0)$ & $85.1(84.7-85.5)$
\end{tabular}

A1: T3-4, PSA $\leq 20 \mathrm{ng} / \mathrm{mL}$, GS 2-7; A2: T1-2, PSA $>20 \mathrm{ng} / \mathrm{mL}, \mathrm{GS} 2-7 ;$ A3: T1-2, PSA $\leq 20 \mathrm{ng} / \mathrm{mL}$, GS 8-10; B1: T3-4, PSA $>20$ ng/mL, GS 2-7; B2: T3-4, PSA $\leq 20$ ng/mL, GS 8-10; B3: T1-2, PSA $\geq 20$ ng/mL, GS 8-10; C: T3-4, PSA >20 ng/mL, GS 8-10. OS, overall survival; PCSS, prostate cancer-specific survival; Cl, confidence interval; LT, local treatment.

and $95 \%$ CI of the intermediate and the poor prognosis group for overall morality were $2.94(2.86-3.03)$ and 5.68 (5.47-5.90). As for the results of PCSS, the 5- and 10-year rate of three groups were $98.9 \%$ vs. $93.8 \%$ vs. $83.1 \%$, and
$95.8 \%$ vs. $85.1 \%$ vs. $66.5 \%$ (Table 2). Compared to the good prognosis group, the HR of the intermediate and the poor prognosis group were 4.21 (3.96-4.48) and 11.36 (10.5912.19). 
A

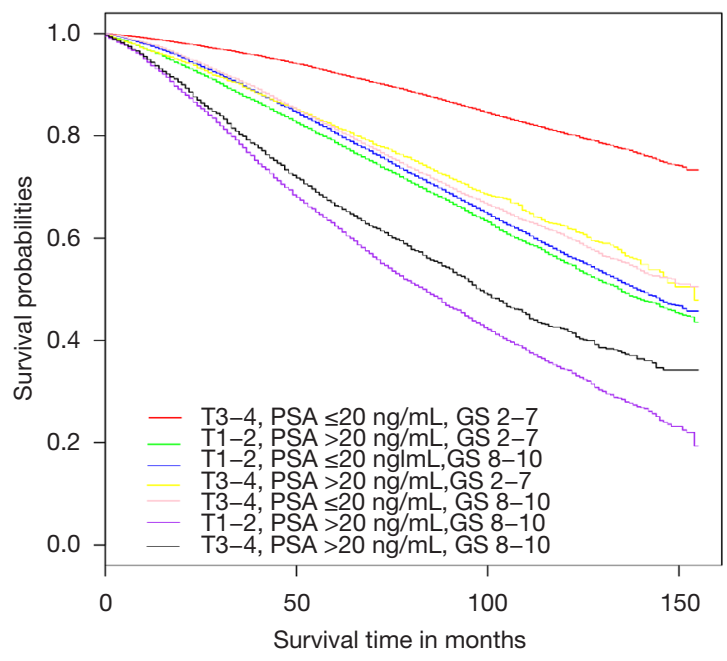

C

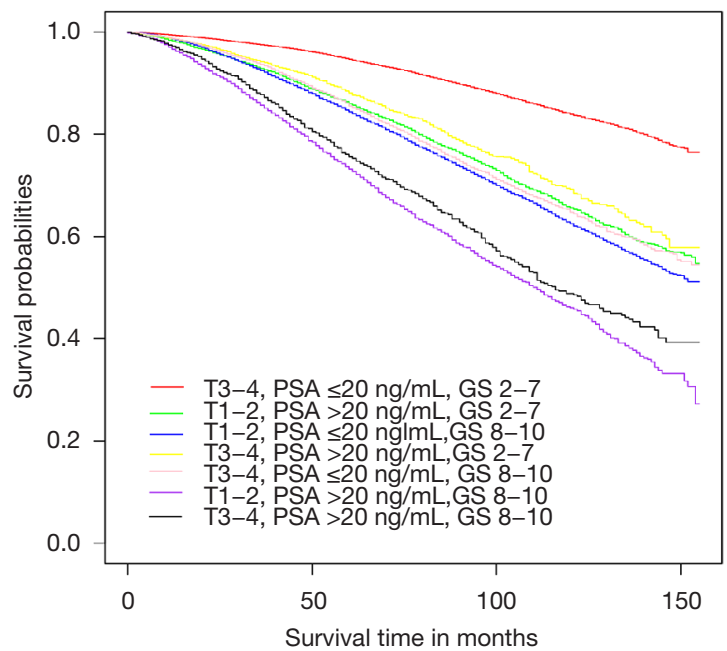

B

Prostate cancer-specific survival curve

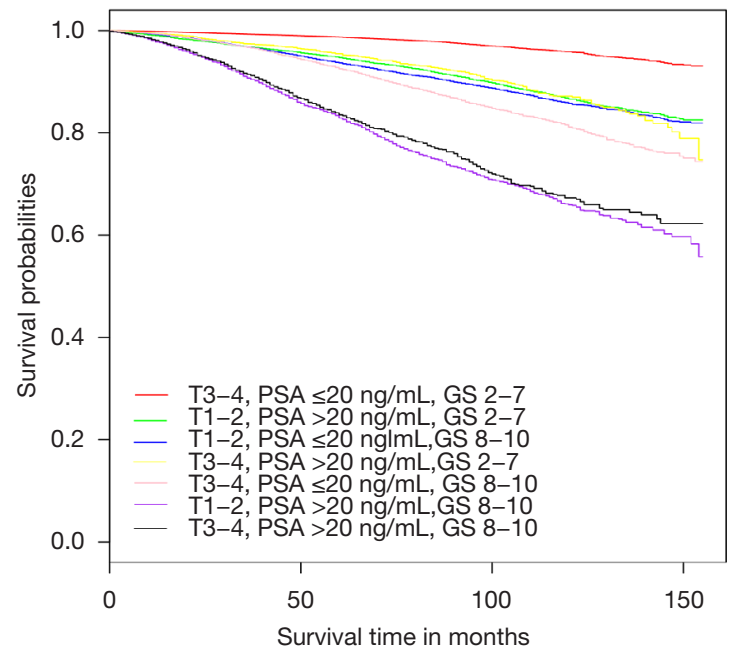

D Prostate cancer-specific survival curve

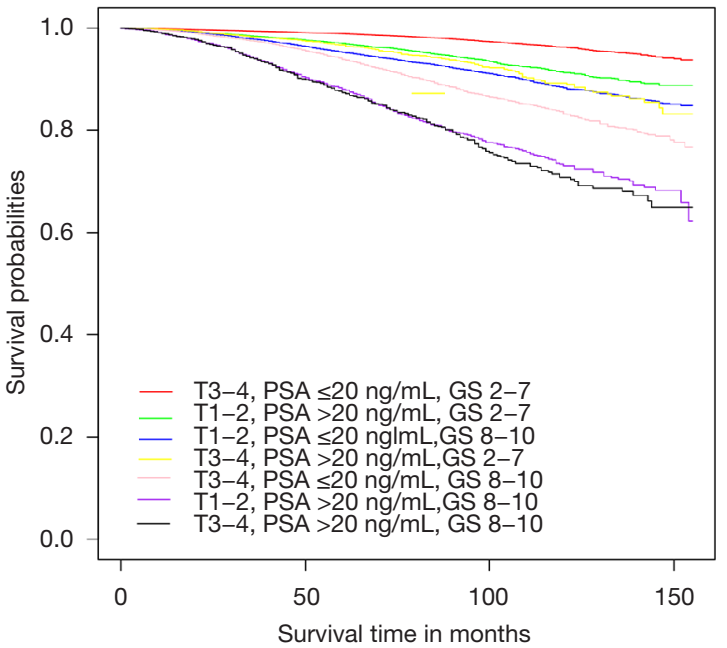

Figure 1 The survival curves of all possible high-risk groups. (A) The OS curve of overall cohort; (B) the PCSS curve of overall cohort; (C) the OS curve of cohort with LTs; (D) the PCSS curve of cohort with LTs. OS, overall survival; PCSS, prostate cancer-specific survival; LT, local treatment; PSA, prostate-specific antigen; GS, Gleason score.

\section{Multivariate Cox analysis}

The results of multivariate Cox regression results for overall mortality and cancer-specific mortality were summarized in Table 4. Univariate Cox analyses showed that the $\mathrm{P}$ values of factors including age, race, marital status, high-risk factors and therapy were $<0.05$. Multivariate Cox regression analysis was conducted with these factors. With A1 as the reference, the $\mathrm{HR}$ and $95 \% \mathrm{CI}$ of $\mathrm{A} 2, \mathrm{~A} 2, \mathrm{~A} 3, \mathrm{~B} 1, \mathrm{~B} 2, \mathrm{~B} 3$ and $\mathrm{C}$ group for overall mortality were $1.71(1.64-1.78), 1.8$ (1.74-1.87), 1.82 (1.7-1.94), 2.06 (1.98-2.15), 2.67 (2.562.8), 2.96 (2.8-3.14). As for the cancer-specific morality, the HR and $95 \%$ CI of A2, A2, A3, B1, B2, B3 and C group were 2.38 (2.19-2.59), 2.96 (2.75-3.18), 2.75 (2.423.11), 4.48 (4.16-4.84), 6.45 (5.94-7.01), 7.7 (7.02-8.45), respectively. 


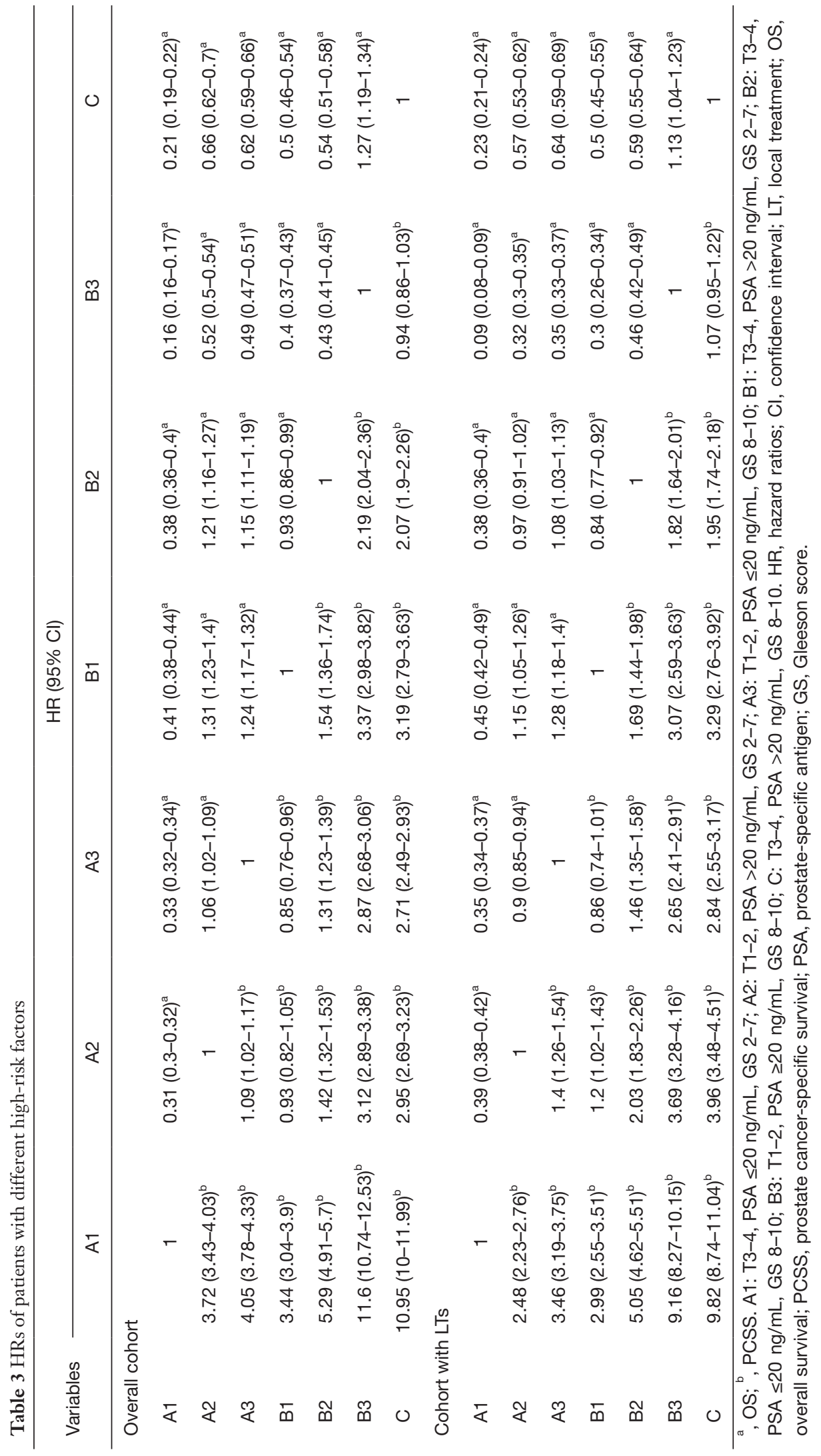


A

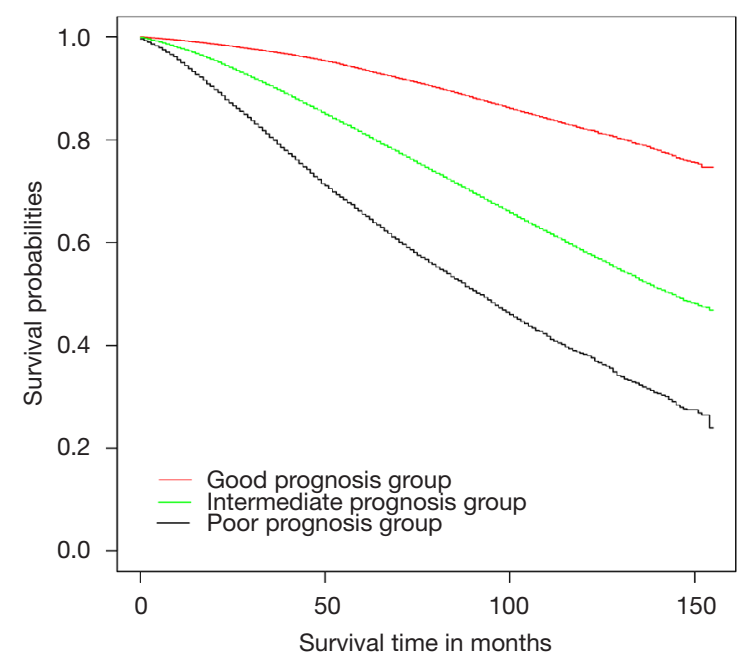

B

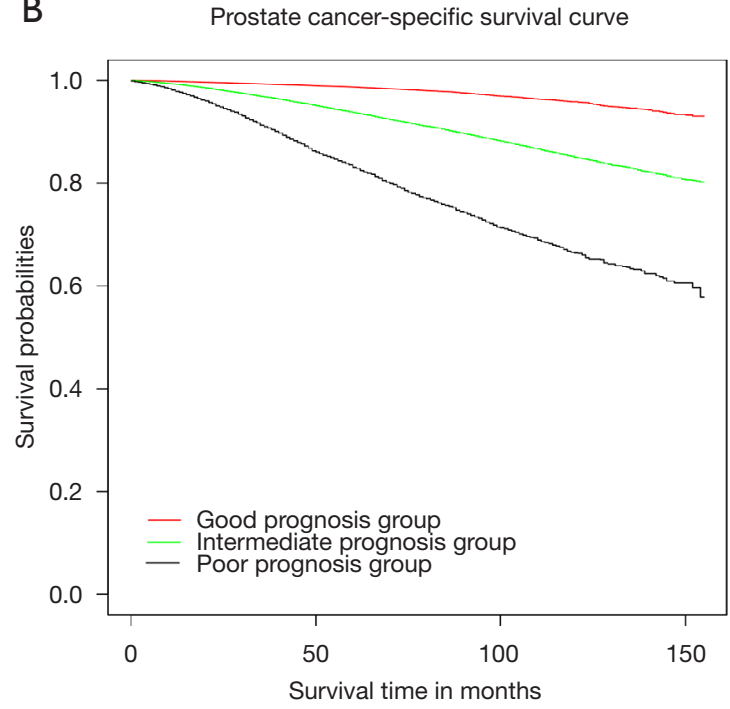

Figure 2 The survival curves of good, intermediate and poor prognosis groups. (A) The OS curve of three prognosis groups; (B) the PCSS curve of three prognosis groups. OS, overall survival; PCSS, prostate cancer-specific survival.

\section{Nomogram predicting model and validation}

The predicting model of nomograms was built with the factors in the multivariate Cox analysis (Figure 3). The $\mathrm{C}$-index of this nomogram was 0.773 , indicating a good discrimination ability of this model. Five- and 10-year calibration curves (Figure 4) also revealed good agreement between the actual observation and the nomogram prediction.

\section{Discussion}

The prognosis of men with high-risk PCa has been investigated in many previous publications. The 10-year PCSS rate of men with localized high-risk $\mathrm{PCa}$ is approximately $90 \%$ (15-17). Detailed high-risk factors and the number of high-risk factors have a great impact on the survival outcome of patients, and only a few studies have reports on this $(13,18-20)$.

A total of 151,799 patients with high-risk PCa were enrolled in our study. The overall 10-year OS and PCSS rates were $65.4 \%$ and $88 \%$ in all patients, and $71 \%$ and $90.6 \%$ in the patients that have undergone LTs. According to the OS and PCSS results, we divided them into three groups: a good prognosis group with only one high-risk factor of T3-4 (A1), an intermediate prognosis group with one factor of PSA >20 ng/mL, or GS 8-10 (A2, A3, B1 and B2), and a poor prognosis group of PSA $>20 \mathrm{ng} / \mathrm{mL}$ and GS
8-10 with/without T3-4 (B3 and C). The 10-year OS and PCSS rate of the three groups were $82.1 \%$ vs. $58.2 \%$ vs. $38.2 \%$ and $95.8 \%$ vs. $85.1 \%$ vs. $66.5 \%$, respectively. Joniau et al. (18) retrospectively analyzed 1,360 high-risk PCa patients treated with radical prostatectomy (RP) with pelvic lymphadenectomy. They developed an extended model of all seven groups and a simplified model of three subgroups: a good prognosis subgroup (one single high-risk factor); an intermediate prognosis subgroup (PSA $>20 \mathrm{ng} / \mathrm{mL}$ and stage cT3-4); and a poor prognosis subgroup (GS 8-10 in combination with at least one other high-risk factor). In their study, the 10-year PCSS rates of the good, intermediate, and poor prognosis subgroups were $95.4 \%, 88.3 \%, 79.7 \%$, and the 10 -year OS rates were $84.0 \%, 68.7 \%$, and $59.1 \%$, respectively. Vagnoni et al. (21) evaluated 615 high-risk PCa patients and found that the 10 -year cancer-specific mortality-free survival rates of men with one, two, three high-risk factors were $92.8 \%, 84.2 \%$, and $27.7 \%$, respectively. Some other studies $(19,22)$ found that significant differences of biochemical failure-free survival existed among the patients with one, two, three high-risk factors of PCa. Walz et al. (13) analyzed 887 highrisk PCa patients treated with RP. They found that the 5 -year BCR survival of only one D'Amico risk factor was $50.3 \%$, compared with $27.5 \%$ for patients with two or more risk factors. Tai et al. (23) revealed that men with only one risk factor had a 5 -year BCR-free survival rate of $76.9 \%$, compared with $34.6 \%$ in men with $\geq 2$ risk factors. Gomez- 
Table 4 Multivariate Cox analysis for patients with high-risk PCa

\begin{tabular}{|c|c|c|c|c|c|c|}
\hline Risk factors & \multicolumn{3}{|c|}{ Overall morality } & \multicolumn{3}{|c|}{ Cancer-specific morality } \\
\hline \multicolumn{7}{|l|}{ Age } \\
\hline$\leq 55$ & 1 & & Ref. & 1 & & Ref. \\
\hline $55-65$ & 1.46 & $(1.38-1.56)$ & $<0.001$ & 1.12 & $(1.03-1.23)$ & 0.014 \\
\hline $76-85$ & 4.6 & $(4.32-4.9)$ & $<0.001$ & 2.15 & $(1.95-2.36)$ & $<0.001$ \\
\hline$>85$ & 8.84 & (8.24-9.48) & $<0.001$ & 3.76 & (3.36-4.22) & $<0.001$ \\
\hline \multicolumn{7}{|l|}{ Race } \\
\hline White & 1 & & Ref. & 1 & & Ref. \\
\hline \multicolumn{7}{|l|}{ Marital status } \\
\hline Married & 1 & & Ref. & 1 & & Ref. \\
\hline Unmarried & 1.3 & $(1.26-1.35)$ & $<0.001$ & 1.34 & $(1.26-1.43)$ & $<0.001$ \\
\hline Divorced & 1.38 & $(1.34-1.42)$ & $<0.001$ & 1.38 & $(1.31-1.46)$ & $<0.001$ \\
\hline \multicolumn{7}{|l|}{ Risk } \\
\hline $\mathrm{A} 1$ & 1 & & Ref. & 1 & & Ref. \\
\hline $\mathrm{A} 2$ & 1.71 & $(1.64-1.78)$ & $<0.001$ & 2.38 & (2.19-2.59) & $<0.001$ \\
\hline \multicolumn{7}{|l|}{ Therapy } \\
\hline $\mathrm{RP}$ & 1 & & Ref. & 1 & & Ref. \\
\hline EBRT & 1.33 & $(1.29-1.38)$ & $<0.001$ & 1.15 & $(1.08-1.22)$ & $<0.001$ \\
\hline Prostatectomy & 1.44 & $(1.36-1.52)$ & $<0.001$ & 1.74 & $(1.6-1.9)$ & $<0.001$ \\
\hline Radiation & 2.18 & $(2.1-2.26)$ & $<0.001$ & 2.27 & $(2.13-2.43)$ & $<0.001$ \\
\hline СОT & 1.89 & $(1.75-2.05)$ & $<0.001$ & 2.68 & (2.38-3.02) & $<0.001$ \\
\hline NDT & 2.28 & (2.05-2.54) & $<0.001$ & 2.52 & (2.09-3.03) & $<0.001$ \\
\hline
\end{tabular}

A1: T3-4, PSA $\leq 20$ ng/mL, GS 2-7; A2: T1-2, PSA >20 ng/mL, GS 2-7; A3: T1-2, PSA $\leq 20$ ng/mL, GS 8-10; B1: T3-4, PSA >20 ng/mL, GS 2-7; B2: T3-4, PSA $\leq 20$ ng/mL, GS 8-10; B3: T1-2, PSA $\geq 20$ ng/mL, GS 8-10; C: T3-4, PSA >20 ng/mL, GS 8-10. PCa, prostate cancer; HR, hazard ratio; Cl, confidence interval; Ref., reference; RP, radical prostatectomy; EBRT, external beam radiotherapy; COT, combined therapy; NDT, no definitive therapy; PSA, prostate-specific antigen; GS, Gleason score. 


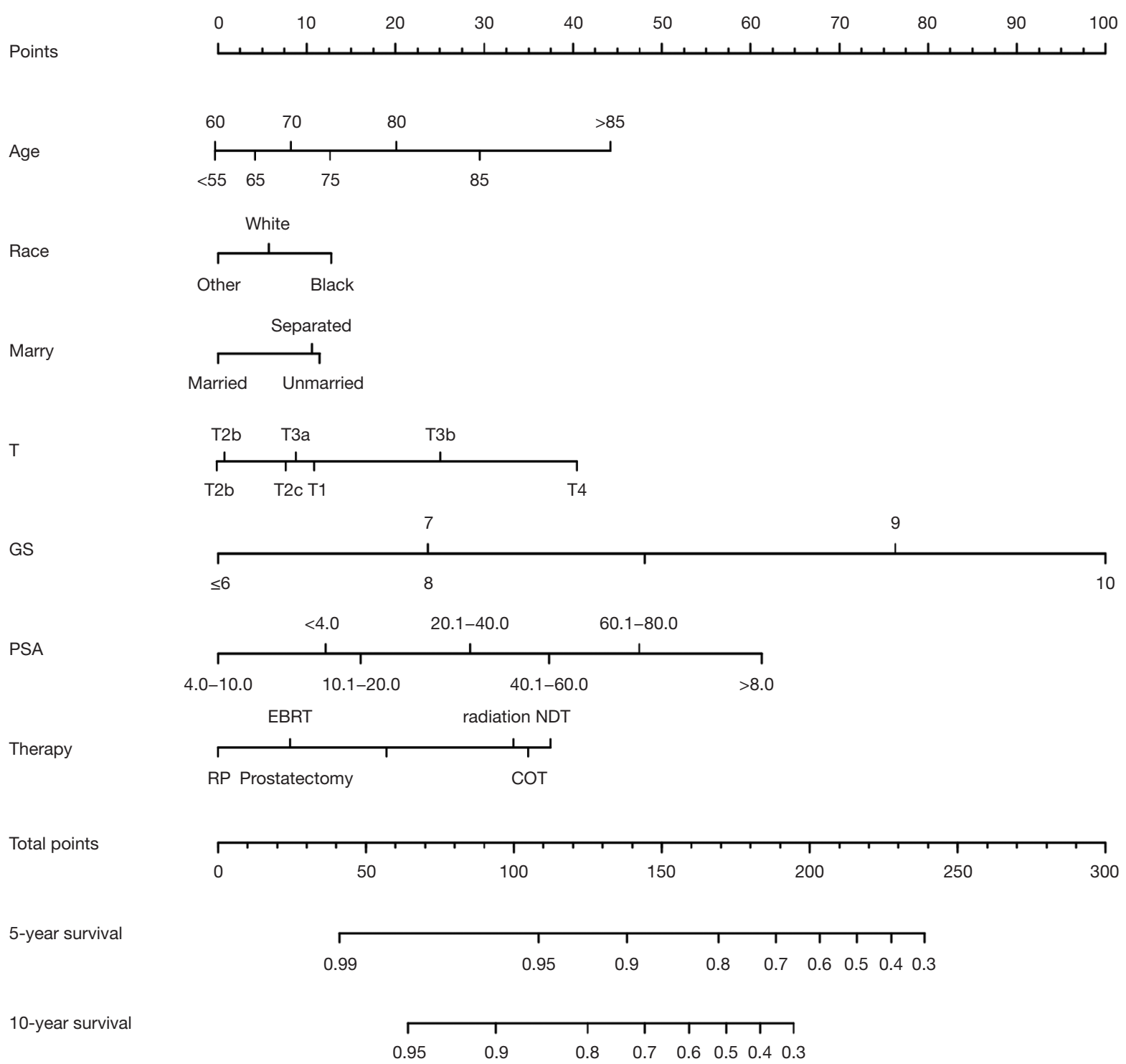

Figure 3 The nomogram model of predicting the probability of PCSS in men with high-risk PCa based on the factors of age, race, marital status, T stage, PSA, GS and therapy. Instructions: Locate the patient's level of every factor on the axis. Draw a line straight upward to the point axis to determine the points received from each factor. Sum all points of each factor and locate the final sum on the total-point axis. Draw a line straight down to find the patient's 5- and 10-year PCSS rates. PCSS, prostate cancer-specific survival; PCa, prostate cancer; PSA, prostate-specific antigen; GS, Gleason score.

Iturriaga et al. (24) identified 1,341 extreme-risk PCa (T3b4, GS $9-10$ or PSA $>50 \mathrm{ng} / \mathrm{mL}$; or patients with two or more high-risk factors: T2c-3a, GS 8 and PSA $>20 \mathrm{ng} / \mathrm{mL}$ ), and the 10-year BCR, clinical-free survival, PCSS and OS were $57.0 \%, 78.9 \%, 93.6 \%$, and $71.3 \%$, respectively.

The PCSS curve of seven groups showed that men with one risk factor of T3-4 had the best survival, and men with one risk factor of PSA $>20 \mathrm{ng} / \mathrm{mL}$ had similar survival outcomes with those with two high-risk factors of T3-4 and PSA $>20 \mathrm{ng} / \mathrm{mL}$. Besides, men with two factors of PSA $>20 \mathrm{ng} / \mathrm{mL}$ and GS 8-10 were associated with similar PCSS with men with all three high-risk factors. These results revealed that clinical $\mathrm{T}$ staging has less impact on the prognosis when compared with other high-risk factors of PSA and GS. The survival outcomes of men with PSA $>20 \mathrm{ng} / \mathrm{mL}$ had obviously better survival outcomes than 

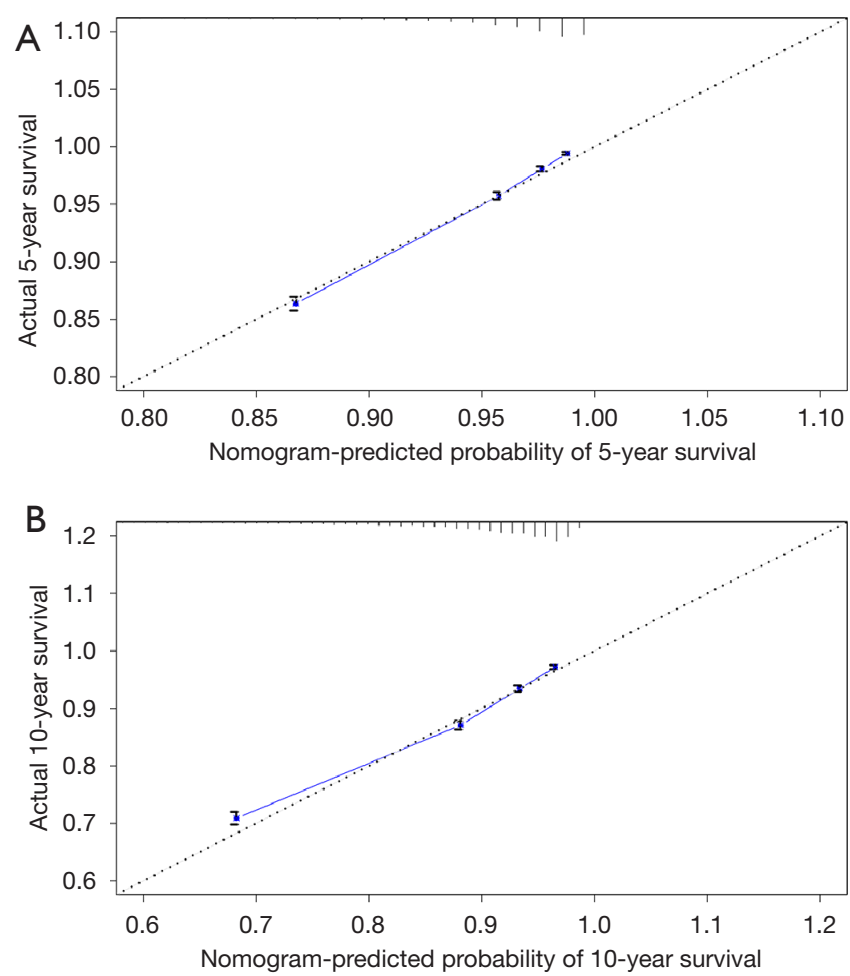

Figure 4 Nomogram calibration curves of the probability of 60 and 120 months PCSS between the prefect prediction and the actual nomogram. The 45-degree gray dotted line indicates a perfect prediction. The blue polyline represented the actual nomogram. (A) Nomogram calibration curves of the probability of 60 months PCSS; (B) nomogram calibration curves of the probability of 120 months PCSS. PCSS, prostate cancer-specific survival.

men with GS 8-10, but were significantly worse than those with T3-4. Men with two high-risk factors of GS 8-10 and T3-4 had significantly worse prognoses than those with PSA $>20 \mathrm{ng} / \mathrm{mL}$ and T3-4. These results revealed that the factor of GS $8-10$ is more aggressive than PSA $>20 \mathrm{ng} / \mathrm{mL}$. Some studies $(18,19)$ reported that GS $8-10$ was the most important predictor of PCa, followed by PSA $>20 \mathrm{ng} / \mathrm{mL}$ and then stage cT3. Walz et al. (13) reported that men with cT3 had the lowest BCR-free survival, followed by men with PSA $\geq 20 \mathrm{ng} / \mathrm{mL}$ and GS 8-10.

Univariate and multivariate Cox analysis showed that age, race, marital status, T stage, PSA level, GS, therapy were the independent risk factors of high-risk PCa. As for the marital status, some studies $(25,26)$ reported it also affect the prognosis of patients. It was acknowledged that marriage likely serves as a multi-faceted proxy for many protective factors including psychosocial support, adherence to follow-up care guidelines along with choice of adjuvant and secondary therapy, healthy lifestyles as so on (27). The nomogram was constructed with risk factors in multivariate Cox analyses. This model is an intuitionistic and convenient tool for predicting survival rates. With this predicting model, the 5- and 10-year survival rates of each patient with high-risk PCa can be estimated. The C-index of our nomogram model was 0.773 , indicating that the model has good accuracy. The 5- and 10-year calibration curves revealed a good agreement between the actual observation and the nomogram prediction.

However, there were some limitations in our study. Firstly, our study was a retrospective analysis in which there were some unavoidable confounders and risk biases. It may interfere with the results. Secondly, our nomogram model was built on high-risk populations and was only applicable to survival prediction of men with high-risk PCa. Thirdly, due to the limitations of the SEER database, many important endpoints such as BCR-free survival, progression-free survival could not be analyzed. Lastly, even though the survival results and the nomogram were conducted with a large cohort and the validation of the nomogram model seemed to be reliable, high-quality studies are still needed for further validations.

\section{Conclusions}

The GS $8-10$ and PSA $>20 \mathrm{ng} / \mathrm{mL}$ was associated with the poorest prognoses in high-risk PCa patients. PCa with three high-risk factors was not more aggressive than that with two high-risk factors of GS $8-10$ and PSA > $20 \mathrm{ng} / \mathrm{mL}$. With the independent risk factors of age, race, marital status, T stage, PSA level, GS, therapy, a predicting model of nomogram was built and validated.

\section{Acknowledgments}

We would like to thanks the SEER program for providing the open-source data.

Funding: This work was supported by a Key Project of National Natural Science Foundation of China; Grant ID: 8177060452; and 1.3.5 project for disciplines of excellence, West China Hospital, Sichuan University, Grant ID: ZY2016104.

\section{Footnote}

Reporting Checklist: The authors have completed the 
STROBE reporting checklist. Available at http://dx.doi. org/10.21037/tcr-20-1578

Peer Review File: Available at http://dx.doi.org/10.21037/tcr20-1578

Conflicts of Interest: All authors have completed the ICMJE uniform disclosure form (available at http://dx.doi. org/10.21037/tcr-20-1578). The authors have no conflicts of interest to declare.

Ethical Statement: The authors are accountable for all aspects of the work in ensuring that questions related to the accuracy or integrity of any part of the work are appropriately investigated and resolved. All data comes from a public database, which removes all patient tags; no ethical approval is required. The study was conducted in accordance with the Declaration of Helsinki (as revised in 2013). Data for this study were obtained from the US NCI SEER database (https://seer.cancer.gov).

Open Access Statement: This is an Open Access article distributed in accordance with the Creative Commons Attribution-NonCommercial-NoDerivs 4.0 International License (CC BY-NC-ND 4.0), which permits the noncommercial replication and distribution of the article with the strict proviso that no changes or edits are made and the original work is properly cited (including links to both the formal publication through the relevant DOI and the license). See: https://creativecommons.org/licenses/by-nc-nd/4.0/.

\section{References}

1. Ferlay J, Soerjomataram I, Dikshit R, et al. Cancer incidence and mortality worldwide: sources, methods and major patterns in GLOBOCAN 2012. Int J Cancer 2015;136:E359-86.

2. Torre LA, Siegel RL, Ward EM, et al. Global cancer incidence and mortality rates and trends--an update. Cancer Epidemiol Biomarkers Prev 2016;25:16-27.

3. Siegel RL, Miller KD, Jemal A. Cancer statistics, 2019. CA Cancer J Clin 2019;69:7-34.

4. Schröder FH, Hugosson J, Roobol MJ, et al. Screening and prostate-cancer mortality in a randomized European study. N Engl J Med 2009;360:1320-8.

5. Thompson IM. Defining high risk prostate cancer--where do we set the bar? A translational science approach to risk stratification. J Urol 2006;176:S21-4; discussion S25-6.
6. Roach M 3rd, Weinberg V, Nash M, et al. Defining high risk prostate cancer with risk groups and nomograms: implications for designing clinical trials. J Urol 2006;176:S16-20.

7. D'Amico AV, Moul J, Carroll PR, et al. Cancer-specific mortality after surgery or radiation for patients with clinically localized prostate cancer managed during the prostate-specific antigen era. J Clin Oncol 2003;21:2163-72.

8. D'Amico AV, Whittington R, Malkowicz SB, et al. Biochemical outcome after radical prostatectomy, external beam radiation therapy, or interstitial radiation therapy for clinically localized prostate cancer. JAMA 1998;280:969-74.

9. D'Amico AV, Cote K, Loffredo M, et al. Determinants of prostate cancer-specific survival after radiation therapy for patients with clinically localized prostate cancer. J Clin Oncol 2002;20:4567-73.

10. Kirkpatrick J. Biochemical outcome after radical prostatectomy, external beam radiation therapy, or interstitial radiation therapy for clinically localized prostate cancer. J Insur Med 1998;30:204-5.

11. Muralidhar V, Chen MH, Reznor G, et al. Definition and validation of "favorable high-risk prostate cancer": implications for personalizing treatment of radiationmanaged patients. Int J Radiat Oncol Biol Phys 2015;93:828-35.

12. Reese AC, Pierorazio PM, Han M, et al. Contemporary evaluation of the National Comprehensive Cancer Network prostate cancer risk classification system. Urology 2012;80:1075-9.

13. Walz J, Joniau S, Chun FK, et al. Pathological results and rates of treatment failure in high-risk prostate cancer patients after radical prostatectomy. BJU Int 2011;107:765-70.

14. Cronin KA, Ries LAG, Edwards BK. The Surveillance, Epidemiology, and End Results (SEER) Program of the National Cancer Institute. Cancer 2014;120 Suppl 23:3755-7.

15. Boorjian SA, Karnes RJ, Viterbo R, et al. Long-term survival after radical prostatectomy versus external-beam radiotherapy for patients with high-risk prostate cancer. Cancer 2011;117:2883-91.

16. Eifler JB, Humphreys EB, Agro M, et al. Causes of death after radical prostatectomy at a large tertiary center. J Urol 2012;188:798-801.

17. Abdollah F, Schmitges J, Sun M, et al. Comparison of mortality outcomes after radical prostatectomy versus radiotherapy in patients with localized prostate cancer: a 
population-based analysis. Int J Urol 2012;19:836-44.

18. Joniau S, Briganti A, Gontero P, et al. Stratification of high-risk prostate cancer into prognostic categories: a European multi-institutional study. Eur Urol 2015;67:157-64.

19. Lee KS, Koo KC, Choi IY, et al. Re-stratification of patients with high-risk prostate cancer according to the NCCN guidelines among patients who underwent radical prostatectomy: an analysis based on the $\mathrm{K}-\mathrm{CaP}$ registry. Cancer Res Treat 2018;50:88-94.

20. Yamamoto S, Kawakami S, Yonese J, et al. Long-term oncological outcome and risk stratification in men with high-risk prostate cancer treated with radical prostatectomy. Jpn J Clin Oncol 2012;42:541-7.

21. Vagnoni V, Bianchi L, Borghesi M, et al. Adverse features and competing risk mortality in patients with high-risk prostate cancer. Clin Genitourin Cancer 2017;15:e239-48.

22. Beauval JB, Roumiguie M, Filleron T, et al. Biochemical recurrence-free survival and pathological outcomes after radical prostatectomy for high-risk prostate cancer. BMC Urol 2016;16:26.

23. Tai HC, Lai MK, Huang CY, et al. Laparoscopic radical

Cite this article as: Song P, Wang J, Shu M, Di X, Li Y, Qing Y, Dong Q. Prognosis of men with high-risk prostate cancer stratified by risk factors: a population-based retrospective cohort study. Transl Cancer Res 2020;9(10):6013-6025. doi: 10.21037/tcr20-1578 prostatectomy monotherapy, a more aggressive yet less invasive option, is oncologically effective in selected men with high-risk prostate cancer having only one D'Amico risk factor: experience from an Asian tertiary referral center. J Endourol 2014;28:165-71.

24. Gomez-Iturriaga A, Cabeza A, Pastor J, et al. The number of risk factors is the strongest predictor of prostate cancer mortality: multi-institutional outcomes of an extreme-risk prostate cancer cohort. Clin Transl Oncol 2016;18:1026-33.

25. Holmboe SA, Priskorn L, Jørgensen N, et al. Influence of marital status on testosterone levels-A ten year follow-up of 1113 men. Psychoneuroendocrinology 2017;80:155-61.

26. Magrin ME, D'Addario M, Greco A, et al. Social support and adherence to treatment in hypertensive patients: a meta-analysis. Ann Behav Med 2015;49:307-18.

27. Khan S, Nepple KG, Kibel AS, et al. The association of marital status and mortality among men with early-stage prostate cancer treated with radical prostatectomy: insight into post-prostatectomy survival strategies. Cancer Causes Control 2019;30:871-6. 